\title{
Present and Future Climate Change in Indian Cardamom Hills: Implications for Cardamom Production and Sustainability
}

\author{
M. Murugan ${ }^{1^{*}}$, P. K. Shetty ${ }^{1}$, A. Anandhi ${ }^{2}$ and R. Ravi ${ }^{3}$ \\ ${ }^{1}$ National Institute of Advanced Studies, Bangalore-560012, India. \\ ${ }^{2}$ Kansas State University, Manhattan, KS 66506, USA. \\ ${ }^{3}$ Indian Institute of Science, Bangalore-560012, India.
}

\section{Authors' contributions}

This work was carried out in collaboration with all authors. Authors MM and PKS formulated and collected data for the study. Authors $A A$ and RR performed statistical analysis and prepared manuscript of the paper. All authors read and approved the final manuscript.

Research Article

Received $21^{\text {st }}$ April 2012

Accepted $30^{\text {th }}$ November 2012

Published $19^{\text {th }}$ January 2013

\section{ABSTRACT}

Aims: This paper examines the interactions between climate parameters and cardamom capsule yield and its sustainability in Indian Cardamom Hills.

Methodology: Temporal trends were evaluated at annual, seasonal and monthly time scale using Mann-Kendall method. Significant trends were identified at annual, seasonal and monthly scale using two tailed Z-Test. The temporal trends were evaluated using the non-parametric Mann-Kendall test. To quantify the slope we used Sen's non-parametric estimator of slope. The significance of the test was evaluated using two tailed Z-Test. A $p$ value of $<0.05$ was used to indicate statistical significance, using two tailed $Z$ test.

Results: Climate warming was significant in the recent decades in the Indian Cardamom Hills, which is recognized as one of the ecologically sensitive and biologically diverse areas. Considerable and significant spatial and temporal variations have occurred in the main climatic elements like air temperature, rainfall and relative humidity in the hill region. Significant positive trend in day-night time temperature has been observed and the trend differed from one station to another. Significant increasing trend was also observed for minimum temperature than maximum temperature and this had caused decline in diurnal temperature. Both winter and summer monsoon rainfall as well as high relative humidity 
had a positive influence on the yield of cardamom. However, the variability in these two types of rainfall was high for the entire region and the trend is negative. The variability of monthly mean precipitation is high for May, December and January under AR4 climate scenario.

Conclusion: The sustainable yield of cardamom may be possible only when the winter and summer rainfall variabilities were minimal. Increasing trend of soil temperature from 0-10 cm depth was recorded, which was significant at $5 \mathrm{~cm}$ depth and can cause considerable negative implications for sustainable cardamom production both in terms of reduced soil moisture availability and altered pest population dynamics.

Keywords: Temperature; rainfall; relative humidity; soil temperature; cardamom.

\section{INTRODUCTION}

Plant systems, and hence crop yield, are influenced by many climatic factors, and these factors, such as rainfall and temperature may act either synergistically or antagonistically with other factors in determining yield. The net change in yield is determined by the balance between negative and positive, direct and indirect effects that can affect production. Indirect effects arise from changes in the incidence and distribution of insect, pests and pathogens [1] and soil properties. In general, climate variables directly affect the occurrence of insect and pest outbreaks and the frequency of these is therefore likely to change in the present and future [2]. Therefore, the interplay of these factors along with the level of intensity of practices decides sustainability of agroecosystems. Performance of crop plants in terms of growth, development, biomass accumulation and yields depends on acclimation ability to the climatic and environmental changes exercising specific tolerance mechanisms that involve a complex network of biochemical and molecular processes [3]. Abiotic stresses such as extreme air temperature, drought and chemical toxicity represent serious limitations to agriculture causing significant yield reduction in major crop species [4]. High temperature is known to disturb plant metabolism of most plants that survive high temperature through prevention and mitigation of overheating and due to the capacity of protoplasm to tolerate high temperature.

Globally, the Asian and Indian monsoons are very important for agricultural activity. Monsoon failure in one season can brought about severe yield reductions of crops in mountain agroecosystems [5]. The IPCC (2001) indicates that climate change is an inevitable process although the magnitude, timing, precise location and direction of these changes remain uncertain. The climate change in the tropics is often expressed to be less than in extra-tropical regions and this is not necessarily the case for e.g. larger than expected variations in the tropical atmospheric energy budget which have profound effect on tropical precipitation and surface temperature [6]. In most tropical forest regions deforestation and degradation will still dominate over climate change effects for at least the medium term (decades) and therefore, the feedbacks between the land use change and local micro climate may play a critical role in determining the viability and sustainability of forest ecosystems $[7,8,9]$. Climate change impacts food production systems, particularly in areas with large vulnerable populations as well as land cover land use change (LCLUC) can influence regional climate dynamics. Change in climatic variability and its impact on food production remains uncertain particularly in the tropics [10]. Lobell et al. [11] have reported that not all maize varieties had responded similarly to climate change. The yield of maize has been increased in cooler sites but significantly reduced in areas where the climate is hotter in Africa. Hence, Biophysical factors such as temperature and rainfall as well as 
relative humidity can strongly affect crop yields [12]. Changes in seasons and its duration are an indicator, as well as an effect of climate change. They reflect variations that are occurring in the cycling of energy in the global environment and profoundly affect the balance of life in ecosystem, impact crop agriculture and water balance of a region. Since the duration of a season directly affects the occurrence of insect and pest outbreaks and the frequency of these is, therefore, likely to change in future which will force us to redesign our pest management strategies. Hence knowing the past changes in seasons helps us for future sustainability of the farming society. In this study seasons are defined based on meteorological variables, namely, rainfall and temperature, as they affect agriculture and the irrigation of the region, and also are commonly used in climate change impact studies.

Species of cardamom are mainly grown in the tropical regions of Africa, Asia, South America and Central America. Among some twelve species of cardamom, aromatic cardamom, which is popularly called "Queen of spices" (Elettaria cardamomum Maton) is commercially dominant in the Indian cardamom hills, western hill ranges of Guatemala as well as Usumbara hills of Tanzania $[13,14]$. In the Indian cardamom hills $(\mathrm{ICH})$ local variety Njallani is widely cultivated covering nearly $80 \%$ of the cardamom reserve under cultivation. The remaining areas are also occupied by selections of other planters and cardamom research stations. The $\mathrm{ICH}$ is one of the global biodiversity hot spots where the majority of the tree species belong to C3 photosynthetic type, where as cardamom has C4 pathway. Most model studies of change in forest vegetation highlight the potential importance of temperature or drought thresholds that could lead to substantial forest decline in the future [15]. Higher air temperature and drought can seriously affect cardamom yields up to $70 \%$ in non irrigated areas, therefore, higher summer temperature coupled with drought episodes are considered the strongest climatic limitations across most cardamom growing regions.

Cardamom is native to tropical rainforests of the Western Ghats of India at an altitude range of $600-1600 \mathrm{msl}$. In these ranges the air temperature show more seasonal variation with an annual average about $23^{\circ} \mathrm{C}$. Rainfall is abundant and well distributed, ranging from 1800$4000 \mathrm{~mm}$ with a dry season lasting three to four months and the atmospheric humidity frequently approaching saturation during the main monsoon months along with dense frost. The optimum mean annual temperature range for cardamom is $18-23^{\circ} \mathrm{C}$ [5]. Above $25^{\circ} \mathrm{C}$ the development and ripening of cardamom capsules are accelerated, often leading to early maturity. Continuous exposure to high day time temperatures, as high as $32^{\circ} \mathrm{C}$, could lead to complete withering of leaves and young tillers. A relatively high air temperature during blossoming (April-May) especially if associated with a prolonged dry season may cause reduced pollination and abortion of cardamom flowers. Air humidity has a significant positive impact on vegetative and flowering phase of the cardamom. On the other hand, the decrease in relative humidity in combination with elevated day time temperature may limit the successful cultivation and higher yields of cardamom. Rainfall, an important climatic element associated with climate change affects cardamom productivity because cardamom is very sensitive to both excess rainfall and drought. Therefore rainfall prediction for future years and decades is of paramount importance in cardamom productivity and yield sustainability. Therefore, extreme temperatures, depending on their intensity, duration and speed of imposition can impair growth as well as of yields of cardamom. Combination of elevated air and soil temperatures found to be more deleterious for cardamom because along with yield reductions pest management becomes more intensive particularly for root grubs, nematodes and white flies [16].

Vast majority of cardamom plantations belong to small to medium holdings which makes the farming activity highly important in providing higher incomes and wealth distribution 
particularly in India and Guatemala. Cardamom under intensive management yields successfully even under nontraditional areas of $\mathrm{ICH}$ where the level of shade ranges from $40-50 \%$. Copious rainfall with normal distribution is often responsible for good harvest in cardamom [17]. Among the commodities of spices, small cardamom has been the second or the third costliest spices in the world. Except for individual climatological station's work published literatures for cardamom on the present and future climate change are scarce and limited than it's nearby hill ecosystems like Palni hills and montane cloud forest systems in Tamil Nadu $[16,18]$. Few studies have reported the change in season length which can influence some phenological changes in crop plants besides affecting water resources. Among climate variables, amount of rainfall and its distribution is the most influential one for cardamom than air temperature [19,5]. Therefore this study has been very relevant to explain the change in climatic elements and implications for cardamom cultivation and sustainability.

\section{MATERIALS AND METHODS}

\subsection{Geographical Location and Details of Agrometeorological Observatories}

Climate data were obtained from various governmental (Agricultural University Station, Forest Department Observatory, Commodity Board Research Stations) and non Governmental Organizations (Planters Association Research Station). The Cardamom Research Station (CRS), Pampadumpara (1978-2007) and the Indian Cardamom Research Institute (ICRI), Myladumpara (1990-2006) United Planters Association of South India (UPASI), Vandiperiyar (1990-2007) provided rainfall and air temperature as well as relative humidity data representing cardamom growing tracts. Fig. 1 shows the boundary of Cardamom Hill Reserves (CHR) in the Indian Cardamom Hills. The data were thoroughly checked before statistical analysis.

Daily rainfall amounts were summed up to obtain monthly, seasonal and annual values. Daily climatic variables namely, maximum and minimum temperature, relative humidity amounts was averaged up to obtain mean monthly, mean seasonal and mean annual values. Diurnal temperature was estimated by subtracting the maximum and minimum temperatures. Statistics that were analyzed on these climatic variables and reported in this paper.

1) Arithmetic mean of climatic variables at annual, seasonal (season 1 represents January to May; season 2 comprises June to September and season 3 pertains to October- December) and monthly time-scale. 2) Temporal trends were evaluated at annual, seasonal and monthly time scale using Mann-Kendall method. 3) The slope of each trend was identified by Sen slope method as a median of all pair wise slopes. 4) Variation in daily temperature range 5) Significant trends were identified at annual, seasonal and monthly scale in using two tailed Z-Test. 6) LOESS procedure was used to reduce the noise inherent in climate data to allow quantitative visual examination of temporal changes in these data. 7) The climatology of rain fall using box plots. 


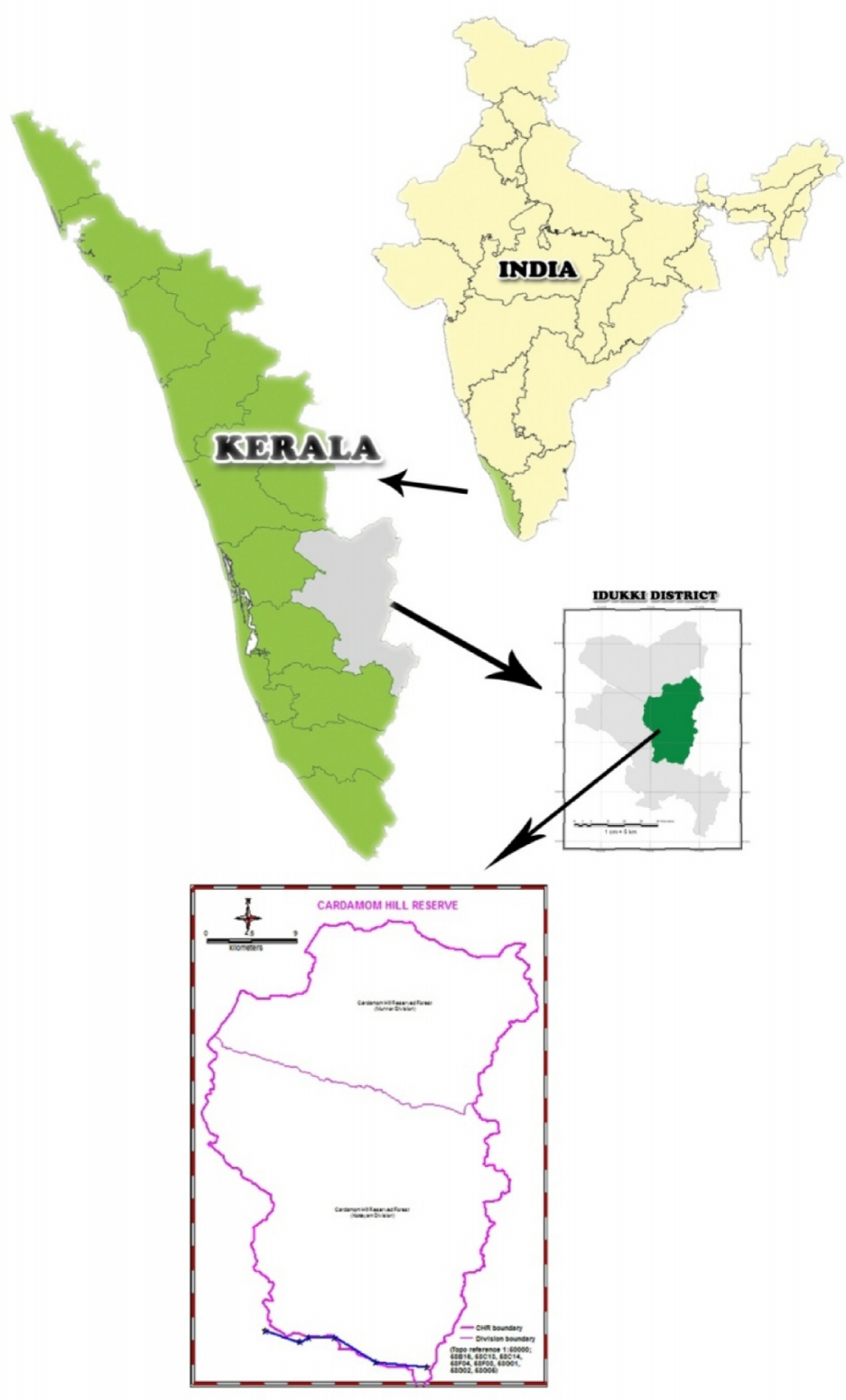

Fig. 1. Map showing the study area of Cardamom Hill Reserves (shaded) in Indian Cardamom Hills, Kerala.

Temporal trends were evaluated using the non-parametric Mann-Kendall test. The advantage of using non-parametric test over parametric test is that they are more suitable for non-normally distributed and censored data which are frequently encountered in meteorological time series [20]. Mann-Kendall test reliably identifies monotonic linear and non-linear trends with outliers [21]. One of the difficulties encountered in the interpretation of the climate data is the quantification of trends (e.g., Calculation of slope). To quantify the slope we used Sen's non-parametric estimator of slope $[22,23]$. This method estimates the 
slope of each trend was identified by Sen Slope method as a median of all pair wise slopes. The significant of the test were evaluated using two tailed Z-Test. The significant level was varied from 1 to 10. In addition, LOESS (Locally weighted scatter plot smooth; [24]) procedure was used to reduce the noise inherent in climate data to allow qualitative visual examinations of temporal changes in these data. LOESS uses a least square regression approach to consider the user defined proportion of the data to weigh each regression point. A $p$ value of $<0.05$ was used to indicate statistical significance, using two tailed $Z$ test.

Box and Whisker plots were prepared to indicate the degree of dispersion and skewness in the data, and identify outliers. Whiskers plot is the convenient way of graphically depicting groups of numerical data through their five number summaries that are the smallest observations, lower quartile (Q1, 5\%), median (Q2), upper quartile (Q3, 95\%) and the largest observations. The span of the box represents the interquartile range of the observed climate variable. The whiskers extend from the box to 5 and $95 \%$ quantiles on the lower and the upper side of the box, correspondingly. Studies have shown that floating seasons reflect 'natural' seasons contained in the climate data better than fixed seasons, especially under changing climate conditions $[25,26]$. Therefore in this study floating season is used to effectively capture the changes in the seasons.

The weather classification methods are used in this study to define floating meteorological season length, link by grouping the monthly data sets of surface climate variables into a finite number of discrete weather types or 'seasons'. In this study the hybrid approach using K-means clustering [27] was used since it had the advantages of both subjective and objective approaches. Hybrid techniques combine elements of empirical and automated procedures for grouping seasons, thereby avoiding time delay and enabling the production of easily reproducible and interpretable results.

\subsection{Global Climate Model (GCM) Simulations for Future Precipitation Change}

The monthly Global Climate Model (GCM) simulations of precipitation, from 20 GCMs and the realizations available are used, for baseline scenario (20CGM) and one future scenario (SRES A1B). GCM simulations are obtained from the World Climate Research Programme's (WCRP's) Coupled Model Intercomparison Project phase 3 (CMIP3) multi-model dataset. The data from all the GCMs for the region surrounding the study region were extracted and regridded to a common $2.5^{\circ}$ using bilinear interpolation using NCAR Command Language (NCL: www.ncl.ucar.edu). The closest grid to the centroid of the study region is used whose latitude is $10^{\circ} \mathrm{N}$ and longitude $77.5^{\circ} \mathrm{E}$. The Time period of baseline scenario is $1978-2000$, while that for future scenario is $2001-2100$. The future time period is divided into 5 time slices namely 2001-2020, 2021-2040, 2041-2060, 2061-2080, and 20812100.

For each month, the change factors are estimated multiplicatively for precipitation for each $\mathrm{GCM} /$ run number for each of the five time slices. The procedure to calculate a CF, multiplicatively, is for a single time slice is explained in this sub-section [28]. The first step is to estimate the mean values of GCM simulated baseline (GCMb) and future (GCMf) climates (equations 3.1 and 3.2). For example, during the temporal domain corresponding to January 1978-2000: for a monthly temporal scale, $N b$ would be equal to the number January months during this time period. For the temporal domain corresponding to January 2001-2020: for a monthly temporal scale, $N f$ would be equal to the number days in all the January months during this time period. 


$$
\begin{gathered}
\overline{G C M b}=\sum_{i=1}^{N b} G C M b_{i} / N b \\
\overline{G C M f}=\sum_{i=1}^{N f} G C M f_{i} / N f
\end{gathered}
$$

Step 2 is to calculate multiplicative change factors $\left(C F_{\text {mul, }}\right)$ (equation 3.3).

$$
C F_{\text {mul }}=\overline{G C M f} / \overline{G C M b}
$$

\subsection{Soil Temperature}

Soil temperature data used in this present study were sourced from the daily weather records of the agro meteorology station, Cardamom Research Station (CRS), Kerala Agricultural University, Pampadumpara. The data were collected for the period 1986-2008. Data for a fixed number of years proceeding the years of 1990, 2000, 2004 and 2008 were averaged to monthly and seasonal values and expressed as the mean values for the periods ending in 1990, 2000, 2004 and 2008. These will henceforth be called the 1990, 2000, 2004 and 2008. The test employed here was the Seasonal Kendall test, a generalization of the Mann-Kendall test. It is a nonparametric test that checks for monotonic trends of the data. Statistical analysis was performed for each parameter studied using MATLAB 7.0.

\section{RESULTS}

\subsection{Air Temperature}

\subsubsection{Air temperature (maximum)}

The annual average surface temperature (1.5 meters) of the planet is probably the single most widely used indicator of the state of the global and local climate. Increasing annual mean maximum temperature trends were noticed across stations (Fig. 2) but significant increase was found for Pampadumpara and Myladumpara stations with 95\% significance. Both Vandiperiyar and Myladumpara reported no significant increase in summer and winter time. However, Pampadumpara site had registered significant increase in during winter season (Table 1 and Fig. 2). At Vandiperiyar, no significant increase was noticed for both summer and winter time temperatures. The increase in summer and winter time temperature was insignificant at Myladumpara site (Table 1). Only at Pampadumpara the increase in winter maximum was reported and was significant both at $95 \%$ and $90 \%$ levels (Table 1 and Fig. 2).

\subsubsection{Air temperature (minimum)}

Both positive and negative trends were reported among the stations examined. Decreasing annual mean minimum temperature trends were noticed for Pampadumpara station for two seasons (summer minimum and winter minimum) and the trend was found to be significant (Table 1 and Fig. 2). Summer and winter minimum temperatures were significant for Pampadumpara and Myladumpara sites and insignificant for Vandiperiyar site (Table 1 and Fig. 2). In Vandiperiyar both positive and negative trends were reported correspondingly for summer and winter minimum temperatures (Table 1). Myladumpara site had reported increasing trend which was significant at $95 \%$ and $90 \%$ levels (Table 1 and Fig. 2). 


\subsubsection{Diurnal temperature}

In tropical mountain system with abrupt and irregular relief, horizontal surfaces are either reduced to small areas or nearly inexistent. Under such circumstances, the concept of regional climate loses most of its value. In this way topoclimates become ecologically meaningful. Therefore, slope angle, slope aspect and relative topographic position play critical role. The first two modify diurnal temperature and humidity through their response to insolation; while topography influences night time climate through its role in downward cold air movement and the daily cycle of slope and valley winds. Larger diurnal temperature was reported for Pampadumpara station for all the three seasons but Myladumpara displayed the negative trend for all the three seasons. Significant trends in diurnal temperature variations at Pampadumpara were reported for the month of August, November and December (Fig. 3).

Table 1. Trend regression and coefficient determination $\left(R^{2}\right)$ values of different rainfall and temperature series of Indian cardamom hills

\begin{tabular}{|c|c|c|c|c|}
\hline \multicolumn{5}{|l|}{ Pampadumpara } \\
\hline & $\mathbf{R}^{2}$ & Trend & $\begin{array}{l}\text { Significance } \\
(95 \%)\end{array}$ & $\begin{array}{l}\text { Significance } \\
(90 \%)\end{array}$ \\
\hline Annual & 0.0048 & -2.44 & NS & NS \\
\hline Monsoon & 0.058 & -8.24 & NS & NS \\
\hline W. Monsoon & 0.0056 & 1.31 & NS & NS \\
\hline Summer(max) & 0.1154 & 0.05 & NS & Yes \\
\hline Winter(max) & 0.2675 & 0.11 & Yes & Yes \\
\hline Summer(min) & 0.2189 & -0.06 & Yes & Yes \\
\hline Winter(min) & 0.1818 & -0.04 & Yes & Yes \\
\hline \multicolumn{5}{|l|}{ Vendiperiyar } \\
\hline Annual & 0.0088 & -7.51 & NS & NS \\
\hline Monsoon & 0.0989 & -18.75 & NS & NS \\
\hline W. Monsoon & 0.0059 & 3.45 & NS & NS \\
\hline Summer(max) & 0.0049 & 0.0074 & NS & NS \\
\hline Winter(max) & 0.1831 & 0.0520 & NS & Yes \\
\hline Summer(min) & 0.0533 & 0.03 & NS & NS \\
\hline Winter(min) & 0.0201 & -0.017 & NS & NS \\
\hline \multicolumn{5}{|l|}{ Myladumpara } \\
\hline & $\mathbf{R}^{2}$ & Trend & $\begin{array}{l}\text { Significance } \\
(95 \%)\end{array}$ & $\begin{array}{l}\text { Significance } \\
(90 \%)\end{array}$ \\
\hline Annual & 0.1656 & -36.282 & NS & NS \\
\hline Monsoon & 0.2453 & -34.83 & Yes & Yes \\
\hline W. Monsoon & 0.0155 & -5.7551 & NS & NS \\
\hline Summer(max) & 0.0132 & 0.014 & NS & NS \\
\hline Winter(max) & 0.1404 & 0.0282 & NS & NS \\
\hline Summer(min) & 0.4068 & 0.32 & Yes & Yes \\
\hline Winter(min) & 0.6131 & 0.301 & Yes & Yes \\
\hline
\end{tabular}


(a) Pampadumpara

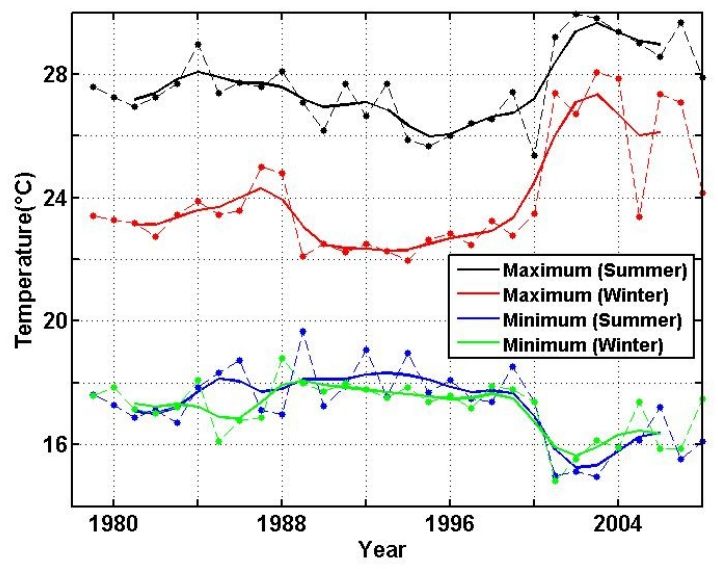

(b) Myladumpara

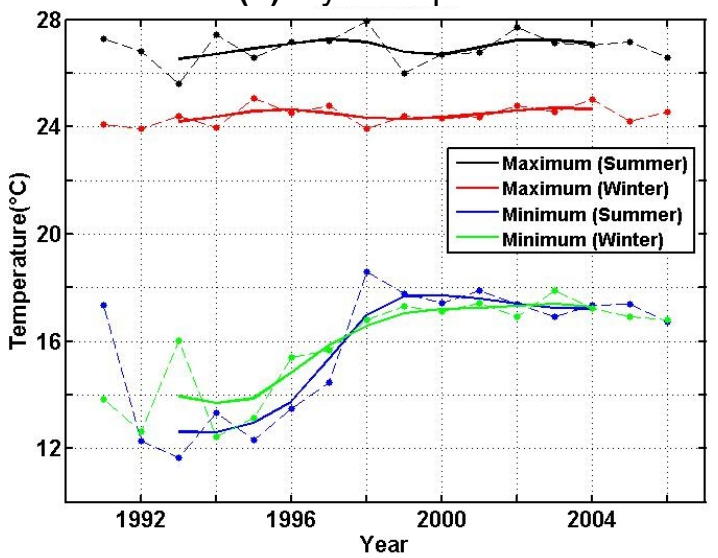

(c) Vandiperiyar

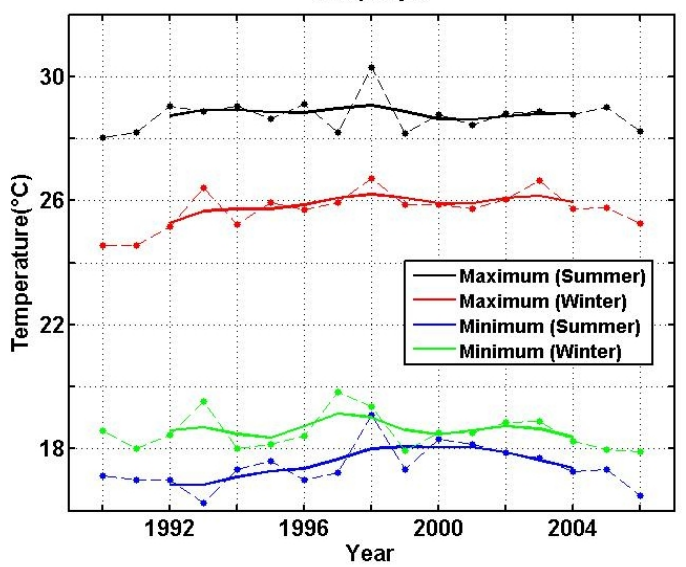

Fig. 2. Time series (smoothed by 5 point binomial filter) of seasonal (summer and winter) temperature of (a) Pampadumpara, (b) Myladumpara and (c) Vandiperiyar 

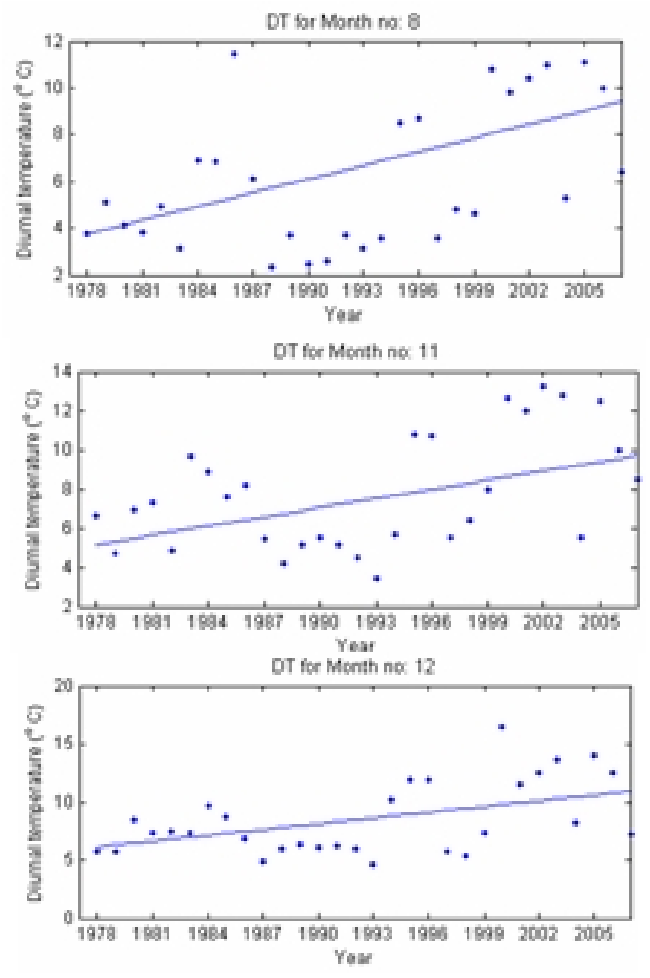

Fig. 3. Significant $(p=0.05)$ trends in diurnal temperature variations at Pampadumpara

\subsection{Rainfall}

The $\mathrm{ICH}$ plateau areas exhibited a tropical rainfall regime with summer rainfall peculiar to equatorial pattern of rainfall. The tropical highland forests are probably most strongly shaped and organized by rainfall and cooling, which have strong correlation with biodiversity and cardamom productivity. All the stations studied the annual rainfall trends were negative but insignificant at $95 \%$ (Table 1 and Fig. 4). Decreasing trend was also noticed in all three sites for summer monsoon rainfall which was significant (95\%) for Myladumpara site (Table 1). Myladumpara had registered negative trend for both annual and southwest as well as winter monsoon rainfall. Vandiperiyar and Pampadumpara sites have reported increasing trend in winter monsoon rainfall and was insignificant at both the sites (Table 1 and Fig.4).

\subsection{Future Rainfall Change in ICH}

Rainfall is one of the most influencing climatic elements for optimum growth and development as well as yield of cardamom. Cardamom is also very sensitive to heavy rainfall and hails, and sometimes, huge crop loss can occur due to this. Future rainfall pattern is very crucial for rain fed cardamom farming in $\mathrm{ICH}$. The box plot shows the variation in percentage change in precipitation given by the various GCMs and realizations (Fig. 5). In general, variability was observed within the different realizations (runs) of the GCM. The fluctuation in percentage change in rainfall was found to vary across months. For the entire period (2001-2100) the summer months (January, February and April) were expected to receive reduced rainfall (Fig. 5). 
(a) Pampadumpara

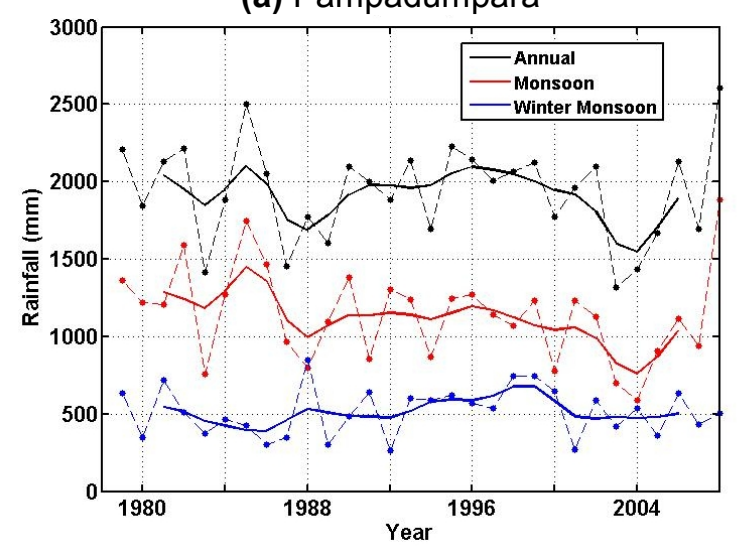

(b) Myladumpara

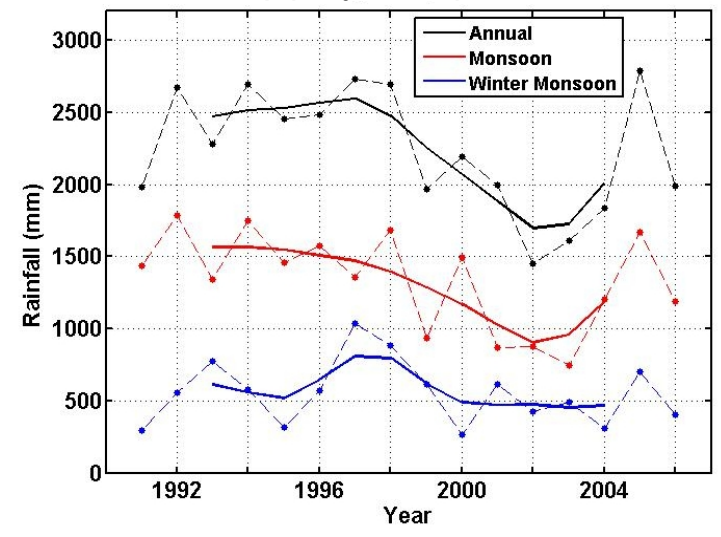

(c) Vandiperiyar

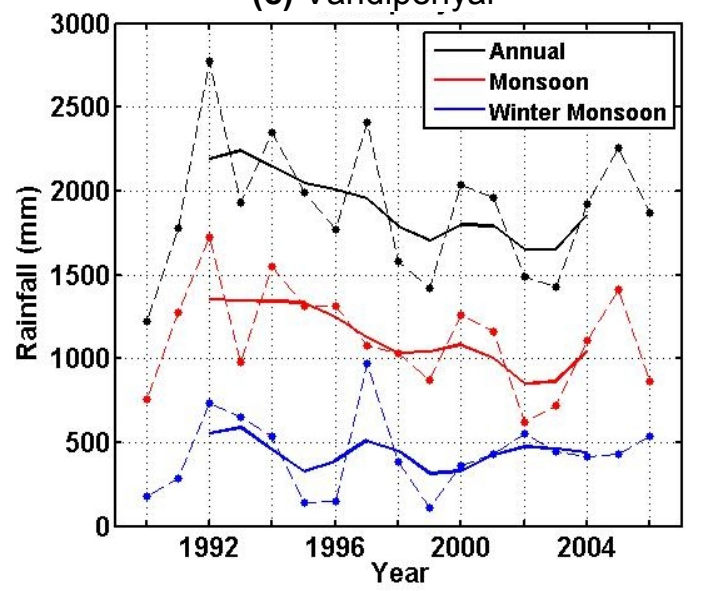

Fig. 4. Time series (smoothed by 5 point binomial filter) of annual and seasonal (summer and winter monsoon) rainfall of (a) Pampadumpara, (b) Myladumpara and (c) Vandiperiyar 

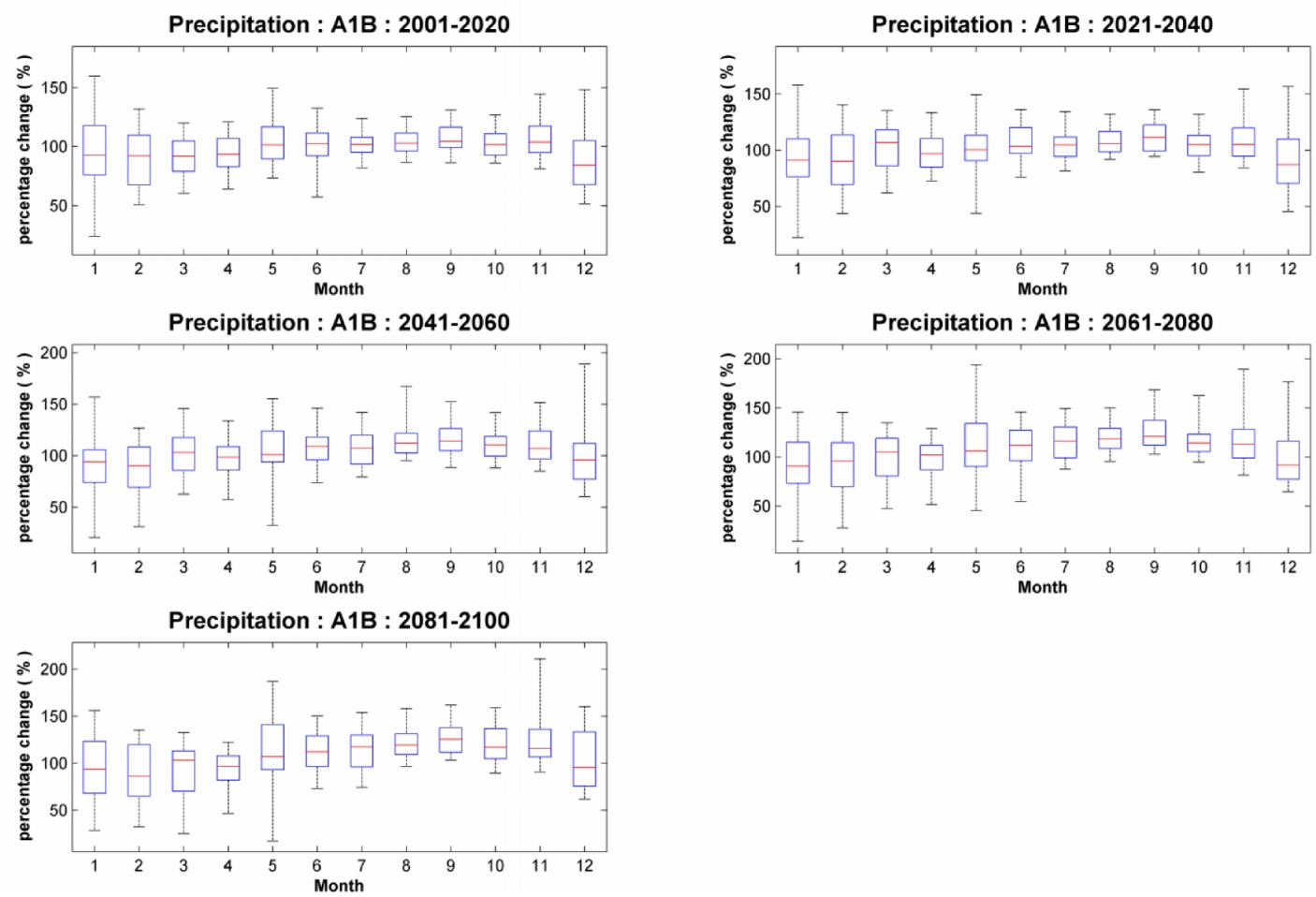

Fig. 5. Box and whisker plots indicate change factors calculated for monthly precipitation for the various AR4 climates. These plots are interpreted as follows: middle line shows the median value; top and bottom of box show the upper and lower quartiles (i.e. 75 and 25 percentile values); and whiskers show the 95 and 5 percentile model values.

Similarly, the last month of the winter monsoon (December) was likely to get reduced precipitation for the whole period (2001-2100). Most GCMs showed an increase in precipitation in the monsoon months (median above $100 \%$ in figure) and decrease in non monsoon months except May (median below $100 \%$ in figure). Increased precipitation was envisaged for May (from 2001 through 2100). Variability in monthly precipitation of January and December for the entire predicted period was found to be noticeable than for other months.

\subsection{Soil Temperature}

Soil temperature data are far more important for understanding various processes like soil nutrient dynamics and soil microbial communities and their activities. Surprisingly, soil temperature data and information are very scarce in the world. Long term soil temperature research, in India are very scanty therefore published literature is quite limited. Temporal variations in soil temperatures at $5 \mathrm{~cm}$ depth are presented in Table 2. Constant increase in soil temperatures for all the three layers was recorded since 1990 through 2008 at Pampadumpara agroclimatological station. Similar positive trends were observed for other seasons as well. Abrupt increases in cumulative mean soil temperatures for all both the seasons were seen in 2004. Monthly soil temperature values of 2004 were also higher for all 
three layers. Considering the whole period, the highest level of soil temperature was reported for March $\left(37.1^{\circ} \mathrm{C}\right.$ ) (Table 2) and the lowest value was $22.2^{\circ} \mathrm{C}$ (Table 2), measured for November. During the report period of this study, the summer months (January-May) have recorded higher temperatures than those of rainy season months (June-December) regardless of soil depths and the period of study. Greater variations in soil temperatures occurred in the top $5 \mathrm{~cm}$ soil layer than the layers beneath it. Minimum variations were noticed for $15 \mathrm{~cm}$ soil depth for the entire period of study. Difference in soil temperature values (seasonal mean) between summer months and rainy months was of the order of $6^{\circ} \mathrm{C}$. Soil temperature values decreased with increasing the depth. Among summer months March and April have reported higher soil temperatures irrespective of time period and soil depth. Soil temperatures were always low for months such as July and August regardless of period and soil layer depth. In soil temperature at depths $5 \mathrm{~cm}$ and $10 \mathrm{~cm}$, a significant upward trend (both with $p<0.05$ ) was noticed. The test statistic was 45 and 46 , respectively, out of a maximum possible value of 72 . At $15 \mathrm{~cm}$ depth, a weaker upward trend was found, but with a less significant $p$ value $(p>0.05)$. The statistic was 12 out of a maximum possible value of 72. Significant soil temperature increase was noticed after 2000 at 5 and $10 \mathrm{~cm}$ depths.

Table 2. Mean monthly and seasonal soil temperatures $\left({ }^{\circ} \mathrm{C}\right)$ (cumulative average) recorded at $5 \mathrm{~cm}$ depth at CRS Pampadumpara from 1990-2008

\begin{tabular}{llllll}
\hline Month & $\mathbf{1 9 9 0}$ & $\mathbf{2 0 0 0}$ & $\mathbf{2 0 0 4}$ & $\mathbf{2 0 0 8}$ & Difference \\
\hline January & 23.3 & 23.6 & 32.3 & 26.4 & 3.1 \\
February & 28.8 & 29 & 34.3 & 30.7 & 1.9 \\
March & 29.3 & 30.6 & 37.1 & 32.3 & 3.0 \\
April & 29.4 & 29.5 & 36.6 & 31.8 & 2.4 \\
May & 25.8 & 27.9 & 31.6 & 28.4 & 2.6 \\
June & 23.8 & 23 & 26.9 & 24.6 & 0.8 \\
July & 22.2 & 23.5 & 25.5 & 23.7 & 1.5 \\
August & 22.3 & 22.4 & 28.7 & 24.5 & 2.2 \\
September & 24.7 & 25.9 & 32.3 & 27.6 & 2.9 \\
October & 24 & 24 & 28.6 & 25.5 & 1.5 \\
November & 23.2 & 23.4 & 27.5 & 24.7 & 1.5 \\
December & 24.6 & 24.7 & 29.5 & 26.3 & 1.7 \\
Season & 1990 & 2000 & 2004 & 2008 & Difference \\
January-May & 27.3 & 28.1 & 34.4 & 29.9 & 2.6 \\
June-December & 23.5 & 23.8 & 28.4 & 25.3 & 1.8 \\
Difference & 3.8 & 4.3 & 6.0 & 4.6 & \\
\hline
\end{tabular}

\subsection{Percentage Capsule Set and Yield of Cardamom}

Capsule set was higher for the monsoon months (south west and north east monsoon) except for December. Average capsule set percentage was almost above 80 for all the months of first monsoon period (Table 3). Lower values of capsule set percentage were registered for summer months (January, February and March). Table 3 showed the variations in temperatures and relative humidity for the percentage capsule set of cardamom. Mean maximum temperature showed clear negative trends while mean minimum temperature apparently recorded positive trends from 14 through $19^{\circ} \mathrm{C}$. There were up trends showed by increased average temperatures for percentage capsule set of cardamom. Relative humidity showed strong positive trends for capsule set (Fig. 6). The highest capsule 
set was reported for the month of November $(84.4 \%)$ followed by September $(84.1 \%)$ and August $(83.1 \%)$. The lowest capsule set percentage was recorded for the month of January (51.1\%).

Table 3. Climatology of mean monthly temperature and relative humidity (2007-2008) on cardamom capsule set (\%) (Average of five plantations with mist and sprinkler irrigation)

\begin{tabular}{|c|c|c|c|c|c|}
\hline Month & $\operatorname{Tmax}{ }^{\circ} \mathrm{C}$ & $\operatorname{Tmin}{ }^{\circ} \mathrm{C}$ & Av.Temp ${ }^{\circ} \mathrm{C}$ & Rh \% & $\%$ Capsule set \\
\hline Jan & 24.3 & 14.1 & 19.2 & 85.5 & 51.1 \\
\hline Feb & 26.3 & 14.8 & 20.6 & 76.8 & 60.2 \\
\hline Mar & 29.0 & 15.9 & 22.5 & 77.6 & 60.4 \\
\hline Apr & 29.8 & 17.8 & 23.8 & 84.9 & 75.5 \\
\hline May & 30.0 & 18.0 & 24.0 & 87.3 & 79.3 \\
\hline Jun & 25.3 & 17.0 & 21.2 & 90.4 & 82.0 \\
\hline Jul & 20.8 & 17.5 & 19.2 & 96.6 & 80.4 \\
\hline Aug & 24.6 & 18.2 & 21.4 & 86.5 & 83.1 \\
\hline Sep & 23.5 & 18.5 & 21.0 & 93.0 & 84.1 \\
\hline Oct & 25.6 & 17.8 & 21.7 & 91.6 & 78.3 \\
\hline Nov & 25.5 & 17.0 & 21.3 & 89.1 & 84.4 \\
\hline Dec & 23.7 & 16.4 & 20.1 & 86.0 & 70.6 \\
\hline
\end{tabular}
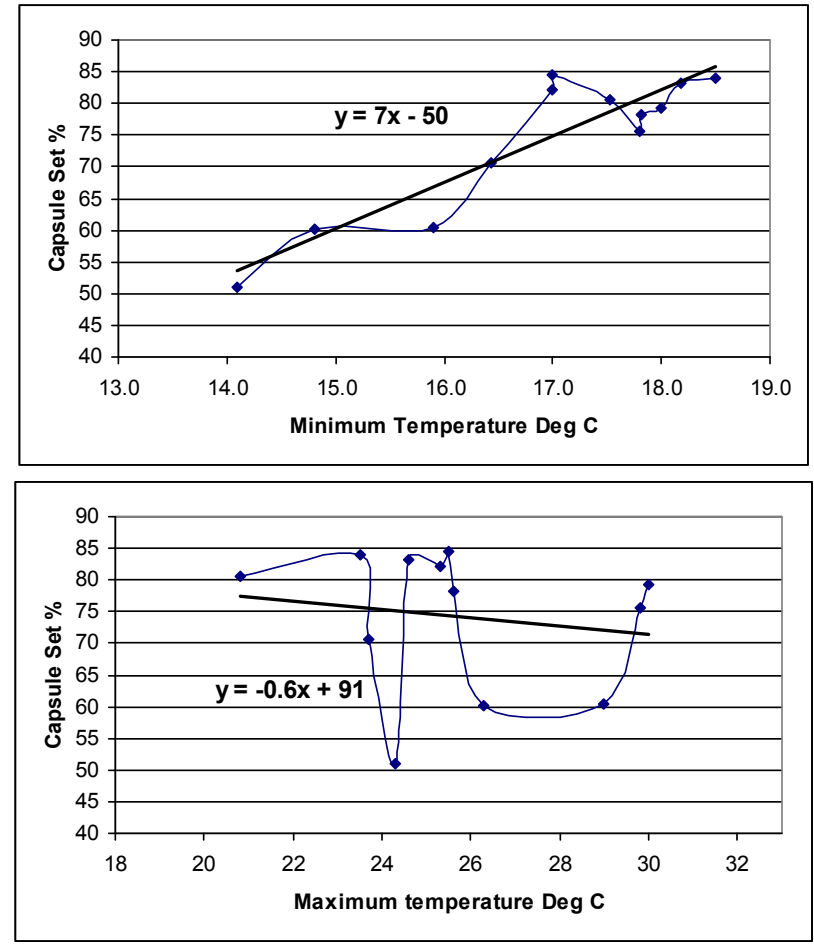

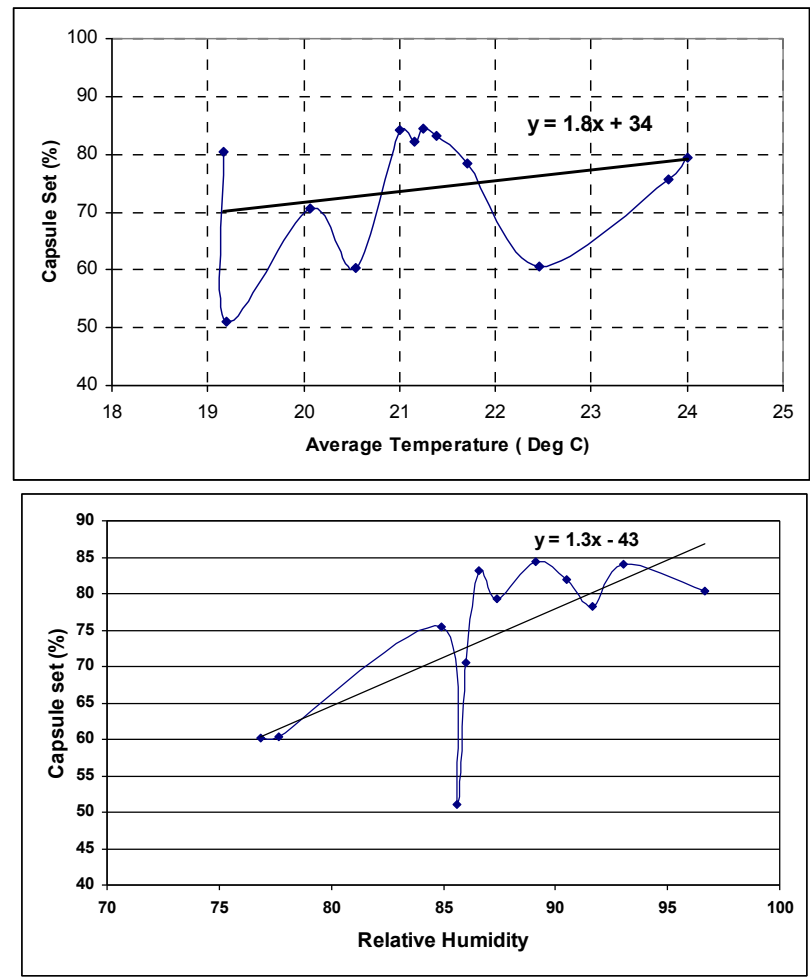

Fig. 6. Trends and influence of temperature and relative humidity on capsule set of cardamom

\section{DISCUSSION}

\subsection{Climate Change and its Implications for Cardamom Farming and Sustainability}

The strong variation in the air temperature of the investigated $\mathrm{ICH}$ region is remarkable compared to the global scale warming. Brohan et al. [29] reported a warming trend of $0.33^{\circ} \mathrm{C} /$ decade for the period $1979-2005$ on land in the northern hemisphere and of $0.27^{\circ} \mathrm{C} /$ decade in both hemispheres. The steady increase is noticed in the mean annual temperature range for Pampadumpara by about $0.1^{\circ} \mathrm{C}$ per year during the period $1978-2007$. The reason for such abrupt increase in temperature climatology for highly disturbed cardamom agro forestry system could be attributed to the lee warming and high velocity direct dry winds experienced by the $\mathrm{ICH}$ plateau. The other two stations namely; Myladumpara and Vandiperiyar, later lie interior in the deep valleys of Periyar Hills than the plateau region of $\mathrm{ICH}$, has experienced decreasing trends of annual mean temperature range $\left(0.16\right.$ and $0.015^{\circ} \mathrm{C}$ per year during the period 1989-2007). Jauregui [30] had reported similar warming trends for other places in related tropical regions where the increase in mean annual temperature range was $0.12^{\circ} \mathrm{C} /$ year (1956-1983). Earlier studies showed an increase of air temperature by $0.3^{\circ} \mathrm{C}$ for $\mathrm{ICH}$ Murugan and Miniraj [31]. The yields of most of our food, feed and fiber crops decline precipitously at temperatures much above $30^{\circ} \mathrm{C}$ [32]. Cardamom, under rain fed condition, can tolerate air temperatures up to $32.2^{\circ} \mathrm{C}$, and beyond this level both growth and development as well as yield is reduced. Analysis of monthly 
temperature regime since 2000 showed temperatures more than $33.5^{\circ} \mathrm{C}$ during the summer. Leaf scorching, reduced growth and development and flowering and increased leaf spot diseases are the common effects of severe warming in $\mathrm{ICH}$. Because of the rise in air temperature coupled with regular thinning of forest trees the soil temperature has increased significantly at least in the top $10 \mathrm{~cm}$. The increased frequency of break periods during monsoon months, with elevated soil temperature, favored soil insect pests like root grubs and plant parasitic nematodes besides white flies and thrips. The root grubs and nematode infestation on cardamom was less severe at least up to 1995 and were considered minor ones. In 1992 and 1993, outbreak of white flies was reported in Kumuli and Mali hot spots of cardamom as of weather change that was conducive for their development. Since then planters have been using lot of pesticides every season for controlling white flies. These pests have become major pests now because of soil-climatic change.

The average yield of cardamom has increased significantly over the last 30 years $(124 \%)$ (1978-2007) [5] and this level of increase in yield was achievable because of phenological changes leading to the continuous flowering habit of the currently popular high yielding variety "Njallani" and the use of improved agronomic practices. An average increase of $4.1 \%$ per year in the yield of cardamom (capsule yield) was recorded that could be stimulated by an asymmetric increase in the mean minimum temperature. IPCC [33] estimated an increase of yield by $0.1 \%$ for every one ppm increase of $\mathrm{CO}_{2}$. However, the unit weight (liter weight) of cardamom has been significantly reduced as a result of reduced duration of grain filling and harvesting. In our analysis liter weight of cardamom (Njallani) varied with the time of harvest. However, our analysis over five places of cardamom hot spots showed considerable reduction in the liter weight. It ranged from $420-490 \mathrm{gm}$ compared to $520-580 \mathrm{gm}$ of earlier report. Similar opposing sensitivities of rice to minimum and maximum temperature were reported across tropical and subtropical Asia [34]. Earlier, cardamom was harvested once in every 50-60 days but in the recent past years, the harvest intervals have been reduced to 30-35 days. Cardamom takes 100-103 days from flowering to capsule harvesting. Because of risk aversion and high market price, planters harvest their crop even at 28-30 days interval. Planters always expect an early harvest and generally wait for 90 days for capsule maturity; therefore there is a loss of 10-13 days for grain development leading to the loss of weight at least by $20-25 \mathrm{mg}$ per capsule. Reduced life span of tillers from 24 months to 18 months and pest infestation could also be contributed to poor grain filling and weight. This can reflect on the reduced grain weight and filling of the harvested capsules. Because of warm air temperatures grain growth rate is accelerated but the duration of grain filling or grain weight is decreased $[35,36]$. The productivity of cardamom has significantly increased over the last 30 years (1978-2007) and it was about $50 \mathrm{~kg} \mathrm{ha}^{-1}$ in the year 1978 while it was about $280 \mathrm{~kg} \mathrm{ha}^{-1}$ for the year 2007 . On the average approximately $7 \mathrm{~kg} \mathrm{ha}^{-1}$ of cardamom has been increased per year (Table 4).

Diurnal temperature variation must be more important for water demanding and sensitive crops like cardamom and rice because the effects of minimum and maximum temperatures on crop phenology and physiology differ significantly at higher levels. Dry season DTR has increased and occurred often on clear sky days in cardamom growing regions. Intense night cooling due to high irradiations loss under cloudless sky could be the main reason. Warming of winter months was faster than summer months and nocturnal warming is the strongest on wet days. This can cause an increased frequency of clear skies and decreased cloudiness or increase in its day-to-day variability. A comparable increase in the amplitude of the warming for the recent period in the high lands of like environments was shown by Pounds et al. [37], which could affect local montane rainfall climatology. Future temperature change was linked to global warming so that it might be characterized by an asymmetry between 
day time maxima and night time minima instead of uniform increase [38]. The increase in temperature would be more pronounced in the night time, leading to decline in daily temperature range. Rosenzweig and Tubiello [39] found that increasing temperature minima as much as maxima would lead to higher yields of wheat in the central USA compared to increasing maxima and minima equally. An increase in night time respiration rates could decrease biomass yield but $1^{\circ} \mathrm{C}$ increase in minimum temperature did not affect the wheat yields in north western India [40]. Overall warming trend in $\mathrm{ICH}$ along with intermittent dry and wet spells during monsoon period and the advancement of dry period or summer at the fag end of December might have caused proliferation of cardamom pest insect population as well as disease causing pathogens. Increased frequency of break periods (during rainy months) is opportune for pest development and the use of pesticide sprays. More than $97 \%$ of the cardamom plantations were affected by perennial pests like cardamom capsule borers and thrips which are highly sensitive to change in climatic elements and their threshold levels [41].

Table 4. Five yearly averages of the mean annual temperature range $\left({ }^{\circ} \mathrm{C}\right)(\mathrm{Tmax}-$ Tmin) and productivity change for the period

\begin{tabular}{lllll}
\hline Pentads & Pampadumpara & Myladumpara & Vandiperiyar & $\begin{array}{l}\text { Productivity } \\
\text { kg/ha }\end{array}$ \\
\hline $1978-1982$ & 7.7 & n.a & n.a & 52 \\
$1983-1987$ & 8.2 & n.a & n.a & 58 \\
$1988-1992$ & 6.3 & 12.2 & 9.6 & 77 \\
$1993-1997$ & 8.3 & 9.3 & 8.0 & 135 \\
$1998-2002$ & 10.5 & 8.3 & 8.8 & 213 \\
$2003-2007$ & 10.8 & 9.0 & 9.3 & 263 \\
Change per year & 0.10 & -0.16 & -0.015 & 7 \\
\hline
\end{tabular}

The warming will increase the use of insecticides because insect pests are more sensitive to warming of atmosphere and soil. Both beneficial and harmful insects and pests will react to warmer conditions, and a general increase in insect abundance is expected in mid latitudes and high altitude tropics. But the main effect could be on the changes in the survival, generation frequency and numbers and distribution boundaries [40]. A considerable negative impact of shade lopping on the microclimate of cardamom has been noticed and the impact is mostly reflected on soil moisture and temperature regimes. The microclimate change along with less available shade favored sucking pests and root feeding soil insect pests for the last 15 years. Planters assume shade lopping can increase cardamom yields through enhancing the photosynthetic activity of cardamom. On the contrary, photosynthesis is maximum during low-light monsoon period (sun hours 4.5 per day against 7.3 hours during summer months) even under severe lopping condition. The photosynthesis is higher (July and August) when soil moisture and nutrients are not limiting. Therefore severe shade lopping for the purpose of increasing photosynthesis is losing its value and purpose. Disappointingly, the regular shade lopping in cardamom plantation is degrading the rainforest structure and function [42]. In ICH none of the forest non pest species was able to establish permanently in cardamom areas. These would be facing extinction because the rainforest cardamom hills disappeared with the expansion of plantation agriculture at $\mathrm{ICH}$. This change in climate system in $\mathrm{ICH}$ could have resulted in the higher incidence of pests thereby planters had been forced to take up management strategies to keep the pests under check. This is the reason why the number of pesticide rounds had gone up to 15-18 (per year) in the first decade of this century. This means that the generation number and 
frequency of incidence of some of the main pests were increased under the current warming. Therefore climatology of temperature and its associated change (by rainfall and relative humidity) in the environment could have played an important role (factor) in deciding the patterns of pesticide consumption on cardamom.

Strong negative trends were observed for summer and winter monsoons as well as increased break periods since 1986 up to 2004, with large spatial variation in ICH [43,44]. Cardamom tracts used to get windblown low intense rainfall and, are highly sensitive to drought and excess rainfall. Both excess rainfall and droughts can increase the incidence of diseases, particularly rot and leaf spot diseases in cardamom. Therefore, use of fungicides could be increased both under drought and excess rainfall situations. In 1998, a rainless period of 103 days during January through March affected cardamom yield by $60 \%$. Recently in 2009 July, hailstones destroyed at least 2500 acres of cardamom crop completely. Interestingly, forest floor crops were not affected by these hailstones in ICH. Cardamom is farmed mostly under rain fed situation therefore, inter annual and seasonal variability in rainfall could affect the sustainability of the cardamom system. Failure of rainfall, particularly in summer could lead to a crop loss of about $60 \%$, if pest management operations are not done properly, the yield loss can increase to $80 \%$. The influence of seasonal rainfall and the levels of fertilizer nutrients on rain fed cardamom yields have been reported by Murugan et al. [45]. The report showed positive correlation with summer rainfall and cardamom yield. In rain fed rice crops from central Java, yield losses from pests were estimated to be $56-59 \%$, with low and unstable yields attributed to drought, nutrient stress and pest management or to a combination of these factors (Boling et al., 2004). Changes in frequency and intensity of rainfalls may also affect pest regulation by predators. Intense rainfall in many agro ecosystems caused substantial mortality of thrips, white flies, aphids and root grubs. Root grubs are favored by low soil moisture and higher soil temperatures which are typical of environment during alternate wet and dry spells of rainy months. In the recent past years it was found that the soil moisture variation in cardamom soils was greater for top $30 \mathrm{~cm}$ soils than the deeper layers $(60$ and $90 \mathrm{~cm})$. The active root mat of cardamom lies in the top $30 \mathrm{~cm}$ soil layer where the activity of root grubs was higher. Root grubs have become permanent root feeding pest in cardamom system during dry spells. Rainy environment for considerable period along with improper drainage could lead to higher incidence of rot diseases and nematode attack in cardamom system. Similar findings were noted in other tropical regions, where variations of the rainfall regimes and alternation of wet and dry seasons increased the spread and abundance of pests on crops [46].

Most GCM runs in our analysis showed an increase in precipitation in the monsoon months and decrease in non monsoon months, except in May for $\mathrm{ICH}$. Variability in the monthly precipitation of January and December for the entire predicted period was found to be noticeable than for other months. In future, the months of December and January will be drier than in the present. This may lead to advancing of summer in $\mathrm{ICH}$ in the coming years. The grid square resolution in GCMs is coarse to represent both high and low precipitation in the windward and leeward sides of the mountains in the Western Ghats. Especially in the mountain regions precipitation simulated are highly dependent upon model resolution [47]. Although the biases present in GCM data hamper reliable climate change impact assessments [48], they still provide the best available means for assessing future changes [49]. Earlier, up to 1980 s planters used to apply only six rounds of pesticides to manage the cardamom pests. In future, we may have to redesign our pest management strategy in order to reduce the environmental cost of pest management in $\mathrm{ICH}$ ecosystem. Similar views on climate change and tropical pest management methods were emphasized by Ciancio and Mukerji [50]. Atmospheric humidity in the cardamom growing tracts of $\mathrm{ICH}$ has increased 
recently mainly due to the injection of water vapor through the irrigation of cardamom plantations. Although this finding of increasing trends of relative humidity in cardamom tracts is contradictory to the law of inverse relationship between air temperature and relative humidity, interestingly many of the intensively irrigated areas showed increasing trends across cardamom hills agro ecosystem. Increased atmospheric humidity increases the release of fungal spores, spore germination and microbial growth leading to higher consumption of fungicides. On the other hand, increased atmospheric humidity causes slower drying of whole plant and leaf surfaces that enhances the photosynthetic rate even under a low environmental light condition. In cardamom, enhanced relative humidity maintains continuous flowering, and the capsule set percentage is maximum. Increased levels of relative humidity can sustain the yield level of cardamom provided appropriate disease management operations are concurrently taken up. One of the most important ecosystem services in $\mathrm{ICH}$ is the pollination of cardamom flowers by honey bees. The activity of honey bees is improved under elevated relative humidity under tropical conditions. The increased activity of honey bees can help improve cardamom yield still under intensive production system [51]. The effects of climate change on crop yields and pests as well as for future rainfall are reported elsewhere for similar environments $[52,53,23]$.

\section{CONCLUSION}

The increase in atmospheric temperature in $\mathrm{ICH}$ is significant from monthly to five yearly scales. Such an increase in the temperature causes the diurnal temperature range to be more negative. The general decrease in precipitation level especially for the monsoon months can affect cardamom productivity as it is sensitive both to drought and excess rainfall. Large uncertainties exists in future rainfall predictions based on GCM has to be considered and interpreted carefully that too in tropical mountain ecosystems like $\mathrm{ICH}$. Significant variability in precipitation patterns both in valleys and peaks of the $\mathrm{ICH}$ can also influence yield productivity of cardamom. The increase in atmospheric temperature is asymmetric as the mean minimum temperature increases faster than the mean maximum temperature. Diurnal temperature variation has more influence on cardamom phenology and productivity. Significant positive response of cardamom yield to summer rainfall and higher mean minimum temperature as well as enhanced relative humidity shows that the currently popular variety Njallani could be a good choice for $\mathrm{ICH}$. Along with atmospheric temperature, the soil temperature is also expected to increase causing enhanced population of rootfeeding soil insect pests. The population dynamics and distribution, as well as the severity or intensity of insect pests and disease-causing pathogens would vary according to the rate of climate change in the $\mathrm{ICH}$, therefore, the current pattern of pesticide use on cardamom and tea would change accordingly, irrespective of the variety in use. As cardamom farming in $\mathrm{ICH}$ continues to modernize and intensify, concerns about the loading of plant nutrients and pesticides on the ecosystem will likely to increase. The pathways of both nutrients and pesticides applied can be extremely complicated in such mountainous agro forest ecosystem, so continued research effort should be placed on better understanding of nutrient dynamics and pesticide degradations to address both agronomic and environmental aspect of the ecosystem. Managing cardamom ecosystem, especially forest and water quality protection and profitable cardamom farming could be the major future challenges.

\section{ACKNOWLEDGEMENTS}

The senior author indebted to the Director, NIAS for providing fellowship during his doctoral research programme. The authors thank the ICRI, Spices Board, Myladumpara and the 
UPASI, Vandiperiyar for supplying climate data. We wish to thank all the cardamom planters who permitted to do experiments in their fields and collect yield data during the study period. We appreciate the help of Dr. Mukund Vasudevan, JNCASR, Bangalore, in the data analysis.

\section{COMPETING INTERESTS}

Authors have declared that no competing interests exist.

\section{REFERENCES}

1. Sutherest RW, Maywold GF, Skarratt DB. Predicting the effects of climate on plants and animals. CSIRD, Melbourne, Australia; 1995.

2. Walker $\mathrm{BH}$. Ecological consequences of atmospheric and climate warming. Clim Chang. 1991;18:01-316.

3. Wang W, Vinocur B, Altman A. Plant responses to drought, salinity and extreme temperatures: towards genetic engineering for stress tolerance. Planta, 2003;218:114.

4. Bray EA, Bailey-Serres J, Weretilnyk E. Responses to abiotic stresses. In: Gruissem W, Buchannan B, Jones R, editors. Biochemistry and molecular biology of plants. Am Soc Plant Phy; 2000.

5. Murugan M, Shetty PK, Ravi R, Anandhi A. Climate change and crop yields in the Indian Cardamom Hills, 1978-2007 CE. Clim Chang. 2011;1573-1480. DOI 10.1007/s10584-011-0115-8.

6. Holmgren M, Scheffer M, Ezcurra E, Gutiérrez JR. El Niño effects on the dynamics of terrestrial ecosystems. Trends Ecol Evol. 2001;16(2):89-94.

7. Barlow J, Peres CA. Ecological responses to EI Nin o-induced surface fires in central Brazilian Amazonia: management implications for flammable tropical forests. Phil Trans Royal Soc B. 2004;359:367-380, DOI 10.1098/rstb.2003.1423.

8. Cramer W, Bondeau A, Schaphoff S, Lucht W. Tropical forests and the global carbon cycle: impacts of atmospheric carbon dioxide, climate change and rate of deforestation. Phil Trans Royal Soc B. 2004;359:331-343. DOI 10.1098/rstb.2003.1428.

9. Laurance WF. Forest-climate interactions in fragmented tropical landscapes, Phil Trans Royal Soc B. 2004; 359:345-352, DOI 10.1098/rstb.2003.1430.

10. Auffhammer M. Agriculture: Weather dilemma for African maize. Nature Clim Change; 2011. doi:10.1038/nclimate1061.

11. Lobell DB, Schlenker W, Costa-Roberts J. Climate Trends and Global Crop Production Since; 1980. Science. 2011 DOI: 10.1126/science.1204531.

12. Moore N, Alagarswamy G, Pijanowski B, Thornton P. East African food security as influenced by future climate change and land use change at local to regional scales. Clim Chang; 2011. DOI: 10.1007/s10584-011-0116-7.

13. Reyes T, Luukkanen O, Quiroz R. Small cardamom-precious for people, harmful for mountain forests. Mount Res Dev. 2006;26(2):131-137.

14. Murugan M, Shetty PK, Ravi R, Subbiah A, Hiremath MB. Environmental impacts of intensive cardamom (small) cultivation in Indian Cardamom Hills: the need for sustainable and efficient practices. Rec Res Sci Tech. 2011;3(2):09-15.

15. Malhi Y, Phillips OL. Tropical forests and global atmospheric change: a synthesis, Phil Trans Royal Soc B. 2004;359:549-555. doi: 10.1098/rstb.2003.1449. 
16. Murugan M, Shetty PK, Mukund V, Panigrahy B. Soil and surface air warming in Cardamom ecosystem in Southern Western Ghats, Kerala, India. Int J Agri Rural Dev. 2009;11(2):52-64.

17. Murugan M, Backiyarani S, Josephrajkumar A, Hiremath MB. Yield of small cardamom (Elettaria cardamomum M) variety PV1 as influenced by levels of nutrients and neem cake under rain fed condition in southern western ghats, India. Casp J Environ Sci. 2007;5(1):19-25.

18. Rangan $\mathrm{H}$, Kull CA, Alexander L. Forest plantations, water availability, and regional climate change: controversies surrounding Acacia mearnsii plantations in the upper Palnis Hills, southern India. Reg Env Change. 2010;10:103-117. DOI 10.1007/s10113-009-0098-4.

19. Anandhi A. Assessing impact of climate change on season length in Karnataka for IPCC SRES scenarios. J Earth Sys Sci. 2010;119(4):447-460.

20. Yue S, Pilon P, Cavadias G. Power of the Mann-Kendall and Spearman's rho tests for detecting monotonic trends in hydrological series. J Hydrol. 2002;259: 254-271.

21. Helsel DR, Hirsch RM. Statistical methods in water resources. Elsevier, Amsterdam; 1992.

22. Sen PK. Estimate of the regression co-efficient based on Kendall's tau. J Am Stat Assoc. 1968;63:1373-1389.

23. Thiel H. A rank variant-method of linear and polynomial regression analysis, part III. In Proc Koninalijke Nederlanse Akademie van Weinenschapten A. 1950;53:1397-1412.

24. Cleveland WS, Devlin SJ. Locally Weighted Regression: An Approach to Regression Analysis by Local Fitting. J Am Stat Assoc. 1988;83(403):596-610.

25. Winkler JA, Palutikof JP, Andresen JA, Goodess CM. The simulation of daily temperature time series from GCM output Part II: Sensitivity analysis of an empirical transfer function methodology. J Climatol. 1997;10(10):2514-2532.

26. Anandhi A, Srinivas VV, Nanjundiah RS, Kumar DN. Downscaling precipitation to River Basin in India for IPCC SRES scenarios using support vector machine. Int J Climatol. 2008;28:401-420.

27. MacQueen J. Some methods for classification and analysis of multivariate observation. Proc. of the Fifth Berkeley Symp. on Mathematical Statistics and Probability, Vol. 1, Le Cam LM, Neyman J. editors. University of California Press: Berkeley. 1967;281-297.

28. Anandhi A. Impact assessment of climate change on hydrometeorology of Indian river basin for IPCC SRES scenarios; PhD thesis, Indian Institute of Science, India; 2007.

29. Brohan P, Kennedy JJ, Harris I, Tett SFB. Uncertainty estimates in regional and global observed temperature changes: a new dataset from 1850. J Geophys Res. 2006;12106-12131.

30. Jauregui E. Aspects of monitoring local/regional climate change in a tropical region. Atmosfera. 1992;5:69-78.

31. Murugan M, Miniraj N, Carmelranijoseph. Changes in climatic elements and their impact on production of cardamom (Elettaria cardamomum M.) in the cardamom hills of Kerala, India. J Spice Arom Crops. 2000;9(2):157-160.

32. Schlenker W, Roberts MJ. Nonlinear temperature effects indicate severe damages to U.S. crop yields under climate change, Proc. Nat Acad Sci, 2009;106(37):1559415598.

33. Intergovernmental Panel on Climate Change (IPCC). Climate change: Impacts, Adaptation and Vulnerability, Contribution of WG II to the third assessment report of the Intergovernmental Panel on Climate Change. Cambridge University Press, Cambridge, UK, 2007. 
34. Welch JR, Vincent JR, Auffhammer M, Moya PF. Rice yields in tropical/subtropical Asia exhibit large but opposing sensitivities to minimum and maximum temperatures. Proc Nat Acad Sci. 2010;107(33):14562-14567.

35. Wiegand CL, Cuellar JA. Duration of grain filling and kernel weight of wheat as affected by temperature. Crop Sci. 1981;21:95-101.

36. Abrol YP, Ingran KT. Effects of higher day and night temperatures on growth and yields of some crop plants. In: Bazzaz F, Sombroek W. editors. Global climate change and agricultural production. Rome: FAO, John Wiley \& Sons. 1996;101-121.

37. Pounds AJ, Fogden MPL, Campbell JH. Biological response to climate change on a tropical mountain. Nature. 1999;398:611-615.

38. Karl TR, Kukla G, Razuvayev VN, Changery MJ. Global warming: Evidence for asymmetric diurnal temperature change. Geophys Res Lett. 1991;18(12):2253-2256.

39. Rosenzweig $\mathrm{C}$, Tubiello $\mathrm{FN}$. Effects of changes in minimum and maximum temperature on wheat yields in the Central US: a simulation study. Agri Forest Meteorol, 1996;80:215-230.

40. Fuhrer J. Agroecosystem response to combinations of elevated $\mathrm{CO}_{2}$, ozone, and global climate change. Agri Ecosys Environ. 2003;97:1-20.

41. Kiritani $K$. The impact of global warming and land-use change on the pest status of rice and fruit bugs (Heteroptera) in Japan. Global Change Biol. 2007;13(8):15861595.

42. Miniraj N, Murugan M. Ecological decline of cardamom hills - an analysis. In: Spices and Aromatic Plants-Challenges and opportunities in the New Century edited by K.V. Ramana et al., Indian Soc Spices, Calicut, 2000;172-176.

43. Jobin T, George A, Celine G, Murugan M. Hydrologic appraisal of small upland watersheds under different land covers. Proc Indian Environ Cong, Thiruvanthapuram. 2004;134-141.

44. Murugan M, Mukund V, Ramesh R, Hiremath MB. Centennial rainfall variation in semi arid and tropical humid environments in the cardamom hill slopes, southern Western Ghats, India. Casp J Environ Sci. 2008;6(2):31-39.

45. Boling A, Tuong TP, Jatmiko SY, Burac MA. Yield constraints of rainfed lowland rice in Central Java, Indonesia. Field Crops Res. 2004;90(2-3):351-360.

46. Olfert $\mathrm{O}$, Weiss RM. Impact of climate change on potential distributions and relative abundance of Oulema melanopus, Meligethes viridescens and Ceutorhynchus obstrictus in Canada. Agri Ecosys Environ. 2006;113:295-301.

47. Pan L-L, Chen S-H, Cayan D, Lin M-Y, Hart Q, Zhang M-H, Liu Y, Wang J. Influences of climate change on California and Nevada regions revealed by a high-resolution dynamical downscaling study. Clim Dynamics, 2011;1-16.

48. Pielke R, Beven KJ, Brasseur G, Calvert J, Chahine M, Dickerson R, Entekhabi D, Foufoula-Georgiou E, Gupta H, Gupta V, Krajewski W, Krider EP, Lau WKM, McDonnell JJ, Rossow W, Schaake J, Smith J, Soroosh S, Wood EF. Climate change: the need to consider human forcings other than greenhouse gases, EOS, Trans-Am Geophys Union. 2009;90:413.

49. Beven K. I believe in climate change cut how precautionary dowe need to be in planning for the future. Hydrol Process. 2011;25,1517-1520. doi:10.1002/hyp.7939.

50. Ciancio A, Mukerji KG. Concepts for plant protection in changing tropical environments general concepts in integrated pest and disease management, Section 1, 2007; 81130.

51. Kraus B, Velthuis HHW. High Humidity in the Honey Bee (Apis mellifera L.) Brood Nest Limits Reproduction of the Parasitic Mite. Varroa jacobsoni Oud. Naturwissenschaften. 1997;84:217-218. 
52. Adams RM, Rosenzweig C, Peart RM, Ritchie JT. Global climate change and U.S. agriculture. Nature. 1990;345:219-224.

53. Rosenzweig C, Iglesias A, Yang XB, Epstein P. Climate change and U.S. agriculture: the impacts of warming and extreme weather events on productivity, plant diseases, and pests. Global Change Human Health. 2000;2:90-104.

(c) 2012 Murugan et al.; This is an Open Access article distributed under the terms of the Creative Commons Attribution License (http://creativecommons.org/licenses/by/3.0), which permits unrestricted use, distribution, and reproduction in any medium, provided the origin al work is properly cited.

Peer-review history:

The peer review history for this paper can be accessed here: http://www. sciencedomain.org/review-history. php? iid $=180 \& i d=10 \&$ aid $=852$ 